\title{
DIVERSITY AND ANTIMICROBIAL ACTIVITIES OF ACTINOMYCETES ISOLATED FROM SOIL SAMPLES OF KODAGU, KARNATAKA STATE (INDIA)
}

\author{
KHANDAN N.D. ${ }^{1}$ AND JANARDHANA G.R. ${ }^{* *}$ \\ 1Department of Studies in Microbiology, University of Mysore, Manasagangotri, Mysore- 570006, Karnataka, India. \\ 2Department of Studies in Botany, University of Mysore, Manasagangotri, Mysore- 570006, Karnataka, India. \\ *Corresponding Author: Email- grjbelur@gmail.com
}

Received: February 18, 2013; Accepted: April 01, 2013

\begin{abstract}
In this study, a total of 158 actinomycetes isolated from 15 soil samples of Kodagu district (Karnataka state) were screened for antimicrobial activities against Gram-positive, Gram-negative bacteria and fungi. A total of $138(87.34 \%)$ isolates showed antimicrobial activity against one or more test organisms. Based on the results of preliminary screening, 65(47\%) isolates showed noticeable antimicrobial activities against test organisms and were selected and identified based on morphological, biochemical and chemotaxonomic characteristics. The potential antibiotic producing actinomycetes identified as Micromonospora spp. (26), Streptomyces spp. (11); Nocardia spp. (9); Actinomadura spp. (7); Rhodococcus spp. (6); Nocardiopsis spp. (4) and Saccharomonospora spp. (2) respectively. This study highlights the occurrence of potential actinomycetes in underexplored habitats of Kodagu region.
\end{abstract}

Keywords- Actinomycetes, Diversity, Antimicrobial activity, Kodagu district

Citation: Khandan N.D. and Janardhana G.R. (2013) Diversity and Antimicrobial Activities of Actinomycetes Isolated from Soil Samples of Kodagu, Karnataka State (India). International Journal of Microbiology Research, ISSN: 0975-5276 \& E-ISSN: 0975-9174, Volume 5, Issue 3, pp.404-409. DOI : 10.9735/0975-5276.5.3.404-409.

Copyright: Copyright@2013 Khandan N.D. and Janardhana G.R. This is an open-access article distributed under the terms of the Creative Commons Attribution License, which permits unrestricted use, distribution and reproduction in any medium, provided the original author and source are credited.

\section{Introduction}

Among microorganisms, actinomycetes are useful biological tools in the production of diverse range of bioactive secondary metabolites such as antibiotics, anticancer, immunosuppressive agents and enzymes with high economic value [1,2]. The role of actinomycetes as sources of bioactive molecules became apparent as these organisms especially Streptomyces provides about $80 \%$ of total antibiotics [3]. Although soil is a natural reservoir for actinomycetes and served as sources of antimicrobial products by pharmaceutical industry for about half a century, only a miniscule fraction of actinomycetes have been used in pharmaceutical industry [4]. Hence, investigation of newer ecosystems for isolation of actinomycetes and for natural product-based drug discovery is crucial to overcome the problem of antibiotic resistance associated with the existing antibiotics.

Kodagu is a district of Karnataka state in Southern India, located

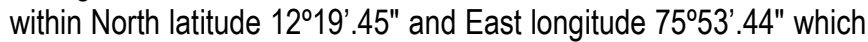
is situated on the eastern slopes of Western Ghats where the range of hills running along Indian's west coast. It occupies about 4100 sq.km. of land in the Western Ghats which is one of the major biogeographical zone of India which has a rich and varied biodiversity. In this rich biodiversity hot spot zone, studies have been carried out in Kerala [5] and Tamil Nadu [6] indicating diverse potent strains of actinomycetes with potential antibacterial activity. In view of the above, study was undertaken to identify the diversity of actinomy- cetes and their antimicrobial properties in soil samples of Kodagu district, Karnataka state, (India).

\section{Materials and Methods \\ Collection of Soil Samples}

Soil samples (15) were collected randomly from three localities of Kodagu district, which includes Kushalnagar taluk (Kaveri Niserghadama forest, Dubare elephant camp, bamboo forest) [latitude $1228^{\prime} .0 \mathrm{~N}$ and longitude 75 58'.0 E], Madikeri taluk [latitude 12 25'.01" N and longitude $7543^{\prime} 60$ " E], Gonikoppa taluk (Titimati) [latitude $1213^{\prime} 18.38^{\prime \prime} \mathrm{N}$ and longitude 75 59' 59.23" E] during July 2010 to June 2011 [Fig-1]. Soil samples collected from different areas comprising of forest areas, agriculture fields and grass lands. In each locality approximately $100 \mathrm{~g}$ of soil was collected from the surface area reaching about $10-15 \mathrm{~cm}$ depth using an open-end soil borer having $20 \mathrm{~cm}$ depth and $2.5 \mathrm{~cm}$ in diameter. The collected soil samples were brought to the laboratory in sterile polythene bags and stored at $4.0^{\circ} \mathrm{C}$ until further analysis.

\section{Soil Analysis}

All the soil samples collected for the isolation of actinomycetes were analyzed for physico-chemical parameters such as $\mathrm{pH}$, electrical conductivity(EC), organic compound(OC), Zinc, Copper, Phosphorous, Potassium, Manganese, Nitrogen, Ferrous and moisture content by suitable methods $[7,8]$. 


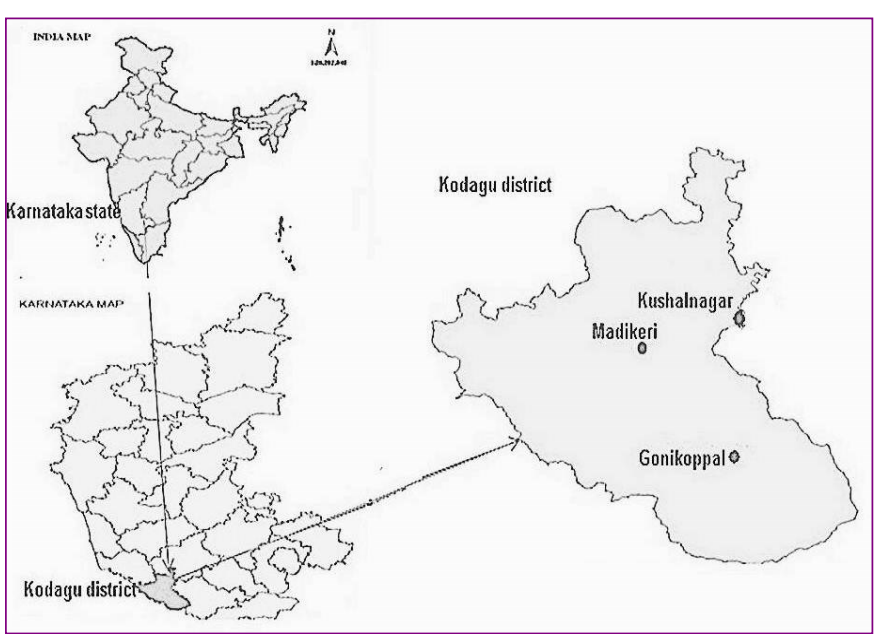

Fig. 1- Location map of various sampling sites in Kodagu district of Karnataka (India)

\section{Pretreatment of Soil Samples}

Soil samples were pretreated by air-drying at room temperature for about 24-48 hours [9]. Further, to enrich the actinomycetes population, one gram of each air dried sample was treated with $1 \%$ $\mathrm{CaCO} 3$ and incubated for 2-3 days in a closed inverted sterile Petri dish to maintain high related humidity [10].

\section{Isolation and Enumeration of Actinomycetes}

Soil samples were subjected to serial dilution method on selective agar medium [11]. The selective medium such as Actinomycetes isolation agar medium (Difco, Hi-Media) composed of ( $\mathrm{g} \mathrm{L}^{-1}$ ) Glycerol; Sodium propionate; Sodium casinate; $\mathrm{KH}_{2} \mathrm{PO}_{4}$; L-Aspargine; $\mathrm{MgSO}_{4} .7 \mathrm{H}_{2} \mathrm{O} ; \mathrm{FeSO}_{4} .7 \mathrm{H}_{2} \mathrm{O}$; agar was used and $\mathrm{pH}$ of the medium was adjusted to 8.1 . The sample was diluted (10-2 to $\left.10^{-5}\right)$ with sterile distilled water and each agar plate was plated with $0.5 \mathrm{ml}$ of dilutions of sample and incubated for 10 days at $28^{\circ} \mathrm{C}$. Typical actinomycetes colonies appeared on the medium were selected based on morphology and sub cultured on Yeast Extract-Malt Extract Agar

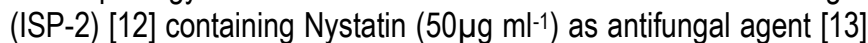
and incubated again at $28^{\circ} \mathrm{C}$ for about $1-2$ weeks. The pure cultures were maintained on Yeast Extract-Malt Extract Agar (ISP-2) slants at $4^{\circ} \mathrm{C}$ and as a spore suspension and mycelium fragments suspension in $20 \%(V / V)$ glycerol at $20^{\circ} \mathrm{C}$ for further studies.

\section{Screening for Antimicrobial Activity}

Isolated actinomycetes were screened for antimicrobial activity against test organisms by using perpendicular streak technique [14]. Colonies were streaked on the center of Modified Nutrient Glucose Agar [15] plates and incubated at $28^{\circ} \mathrm{C}$ for 4 to 5 days, then the test microorganism was inoculated perpendicular to the Actinomycetes and plate was incubated at $37^{\circ} \mathrm{C}$ for $24 \mathrm{~h}$ for bacteria and at $28^{\circ} \mathrm{C}$ for $48 \mathrm{hrs}$. for fungi. The zone of inhibition was determined using millimeter scale and expressed as percentage inhibition.

\section{Test Microorganisms}

The test organisms employed include Gram-positive Staphylococcus aureus (MTCC 96), Bacillus subtilis (MTCC 121) and Gramnegative Escherichia coli (MTCC 729), Enterobacter aerogenes (MTCC 2829) and Aspergillus niger. All the test organisms used in this study were obtained from the Microbial Type Culture Collection (MTCC), Institute of Microbial Technology (IMTECH), Chandigarh-
India, and A. niger was isolated and identified in Mycology Laboratory, Department of Studies in Botany, University of Mysore.

\section{Identification of Actinomycetes}

The cultural and morphological characteristics of each actinomycetes was studied on Yeast Extract-Malt Extract Agar medium (ISP2) and Glycerol- Aspargine Agar (ISP-5) medium [12-16]. Colony characters such as shape, consistency, color of aerial and substrate mycelium and formation of diffusible pigments were considered. A microscopic characteristic of each isolate was also carried out by Grams staining method [17] and cover slip culture technique [16]. The nature of aerial and substrate mycelium, arrangement of spore chain (conidia and arthrospore) were also studied.

Catalase test, Nitrate reduction, Starch hydrolysis, Citrate utilization, Urea hydrolysis [18], Gelatin hydrolysis, Production of melanin pigmentation on Peptone - Yeast Extract Iron Agar (ISP-6) [19] and chemotaxonomic property contains analysis of isomers (2-6 diaminopimelic acid, DAP) in the whole cell hydrolysates by Thin Layer Chromatography technique [20] were studied as biochemical and chemotaxonomic characters for the identification.

\section{Statistical Analysis}

The correlation coefficient analysis between physico-chemical parameters of soil samples and total actinomycetes population (TAP), using Pearson's correlation coefficient (PCC) was analyzed using statistical package SPSS. Frequencies of each genus of actinomycetes were calculated for each site [Eq-1] and all studied areas [Eq2]. Richness [Eq-3] and diversity [Eq-4] of each genus were also calculated for all sites [21].

Frequency for Certain genus in all sites $=\frac{\text { No. of Individual of specific genusin all site }}{\text { TotalNo. of isolates of all site }} \times 100$
Frequency for Certain genus per certain site $=\frac{\text { No. of Individual of occured genus in certain site }}{\text { Total No. of isolates of this site }} \times 100$ (2)
Richness $=$ Total number of generain certaincommunity
Diversity $=\frac{\mathrm{S}-1}{\log n}$

$\mathrm{S}=$ number of genera in each site.

$\log n=$ total number of all individuals isolated in all sites.

\section{Results}

[Table-1] illustrates the total count of actinomycetes in each site and physico-chemical characteristics of soil. The serial dilution of soil samples showed that the population of actinomycetes ranged from $9.6 \times 10^{3}$ to $1.2 \times 10^{3} \mathrm{CFU} / \mathrm{g}$ in soil samples collected from 15 different areas of Kodagu district. The study revealed that Site 2 recorded highest counts of actinomycetes per gram soil followed by site 1 and 11 respectively. However, site 5 and 9 recorded the lowest number of colony count per gram of soil. It was found that, there was correlation co-efficient between physico-chemical properties of soil and total actinomycetes population (TAP) [Table-1], [Table-2]. The higher counts of actinomycetes were recorded in site 2 with percent of organic carbon $(r=0.764 ; p<0.05)$ and $\operatorname{copper}(r=$ $0.900 ; p<0.05$ ). Percent of moisture content of soil studied was also positively correlated with actinomycetes counts $(r=0.956 ; p<$ 0.05).

Among 158 actinomycetes isolated from all studied sites, 65 (47\%) isolates showed noticeable antimicrobial activities (at least against three test organisms) were selected and identified as genus: Micromonospora (26) (formed a single spore at the tip of sporophore on substrate mycelium) followed by Streptomyces (11) (formation of 
long chain of spores); Nocardia (9) (Fragmented mycelium both in substrate and aerial); Actinomadura (7) (short chains of straight and open hooked chains); Rhodococcus (6) (mass of coccid structures); Nocardiopsis (4) (aerial mycelium totally sporulated with fragmenting substrate mycelium); Saccharomonospora (2) (single spore on unbranched aerial mycelium). All the isolates belonging to seven families such as Micromonosporacea, Streptomycetaceae, Nocardiaceae, Micrococcaceae, Thermonosporaceae, Nocardiopsaceae and Psedunocardiaceae respectively. The cultural, morphological, biochemical and chemotaxonomic properties of each actinomycetes isolates is presented in [Table-3]. The occurrence and distribution of these genera is also presented in [Table-4]. Frequencies of each genus in all samples collected from the studied area indicated that the frequency of the genus Micromonospora was $40 \%$ followed by
Streptomyces (17\%), Nocardia (14\%), Actinomadura (11\%), Rhodococcus $(9 \%)$, Nocardiopsis $(6 \%)$ whereas the genus Saccharomonospora showed low percentage of frequency (3\%) [Fig-2]. The percentage frequency of bioactive actinomycetes genera in 15 studied areas in Kodagu district is presented in [Fig-3]. Among the genera recorded, Micromonospora was prevalent in most sites and site 2 recorded the highest frequency percentage (64\%). Beside Micromonospora, the frequency of genus Streptomyces varied from 12.5 to $50 \%$. The genus Nocardia recorded a range of frequency from 9 to $50 \%$. Genus Actinomadura recorded the highest value of frequency in site 8 (60\%). The genus Nocardiopsis and Rhodococcus were recorded in frequencies ranging from (12.5 to $33 \%$ ) and (17 to $50 \%$ ) respectively. However Saccharomonospora was recorded at low frequency percent which ranged from 0 to $3 \%$ [Fig-3].

Table 1-Physico-chemical properties of different soil samples of Kodagu district

\begin{tabular}{|c|c|c|c|c|c|c|c|c|c|c|c|c|}
\hline Collection area & Total Actinomycetes count gm-1 soil & pH & OC & $\mathbf{N}$ & P205 & $\mathrm{K} 20$ & EC & $\mathbf{Z n}$ & $\mathrm{Cu}$ & Mn & $\mathrm{Fe}$ & Moisture of soil \\
\hline Kushalnagar A & $9.20 \times 10^{3}$ & 7.6 & 0.9 & 0.1 & 4 & 91 & 0.1 & 0.3 & 1.62 & 5.45 & 3.15 & 9 \\
\hline Kushalnagar $\mathrm{A}$ & $9.6 \times 10^{3}$ & 7.4 & 1.4 & 0.279 & 4 & 123 & 0.2 & 0.14 & 1.71 & 6.9 & 5.1 & 10 \\
\hline Gonikoppa A & $7.60 \times 10^{3}$ & 8 & 0.42 & 0.12 & 2.9 & 94 & 0.21 & 0.21 & 0.93 & 10.4 & 6.9 & 7.4 \\
\hline Kushalnagar F & $3.00 \times 10^{3}$ & 6.85 & 0.11 & 0.27 & 1.2 & 90 & 0.23 & 0.16 & 0.63 & 2.5 & 4.1 & 5 \\
\hline Gonikoppa F & $1.75 \times 10^{3}$ & 7.6 & 0.1 & 0.69 & 3 & 93 & 0.2 & 0.11 & 0.39 & 3.1 & 4 & 4.1 \\
\hline Kushalnagar-Kaveri niserghadama) F & $2.10 \times 10^{3}$ & 7.9 & 0.1 & 0.16 & 4 & 63 & 0.3 & 0.19 & 0.43 & 6.8 & 7.5 & 4.15 \\
\hline Madikeri F & $2.15 \times 10^{3}$ & 7.8 & 0.1 & 0.14 & 5 & 96 & 0.28 & 0.136 & 0.54 & 12.3 & 7.91 & 5 \\
\hline Madikeri F & $3.85 \times 10^{3}$ & 8 & 0.11 & 0.1 & 2 & 83 & 0.15 & 0.33 & 0.63 & 10.1 & 8.34 & 5.35 \\
\hline Gonikoppa F & $1.2 \times 10^{3}$ & 7 & 0.1 & 0.83 & 5 & 57 & 0.3 & 0.14 & 0.34 & 7.88 & 7.9 & 4 \\
\hline Gonikoppa G & $6.8 \times 10^{3}$ & 8.3 & 0.13 & 0.9 & 3 & 66 & 0.4 & 0.19 & 0.78 & 5.2 & 7.1 & 6.44 \\
\hline Kushalnagar - Kaveri Nisarghadama G & $8.3 \times 10^{3}$ & 7 & 0.74 & 0.12 & 2 & 73 & 0.1 & 0.3 & 1.57 & 8.94 & 7.39 & 8.2 \\
\hline Madikeri G & $4.80 \times 10^{3}$ & 8.5 & 0.12 & 0.14 & 7 & 75 & 0.2 & 0.23 & 0.74 & 1.64 & 7.11 & 6 \\
\hline Gonikoppa A & $8.10 \times 10^{3}$ & 7.9 & 0.57 & 0.64 & 4 & 80 & 0.1 & 0.2 & 1.51 & 11.8 & 5.43 & 8 \\
\hline Madikeri A & $7.52 \times 10^{3}$ & 7 & 0.28 & 0.8 & 2 & 69 & 0.3 & 0.3 & 0.91 & 2.13 & 11.7 & 6.6 \\
\hline Madikeri A & $6.75 \times 10^{3}$ & 8.2 & 0.13 & 0.4 & 3 & 64 & 0.2 & 0.4 & 0.76 & 6.08 & 10.1 & 6.4 \\
\hline
\end{tabular}

The parameter N, P, K are expressed in kg/acrel; Fe, Mn, Cu are in ppm; moisture content in percent

Table 2- Correlation Co-efficient between physico-chemical properties of soil samples and total actinomycetes population

\begin{tabular}{|c|c|c|c|c|c|c|c|c|c|c|c|c|}
\hline & $\mathrm{pH}$ & $O C$ & $\mathrm{~N}$ & P205 & K2O & EC & $\mathrm{Zn}$ & $\mathrm{Cu}$ & Mn & $\mathrm{Fe}$ & Moisture & TAP \\
\hline $\mathrm{pH}$ & 1 & & & & & & & & & & & \\
\hline loc & -0.244 & 1 & & & & & & & & & & \\
\hline $\mathrm{N}$ & -0.16 & -0.239 & 1 & & & & & & & & & \\
\hline P2O5 & 0.444 & -0.04 & -0.084 & 1 & & & & & & & & \\
\hline K2O & -0.93 & $0.612^{*}$ & -0.391 & -0.26 & 1 & & & & & & & \\
\hline EC & 0.061 & -0.492 & 0.505 & 0.71 & -0.337 & 1 & & & & & & \\
\hline $\mathrm{Zn}$ & 0.184 & 0.019 & -0.238 & 0.291 & -0.36 & -0.366 & 1 & & & & & \\
\hline $\mathrm{Cu}$ & -0.136 & $0.908^{* *}$ & -0.221 & -0.075 & 0.422 & $-0.609^{*}$ & 0.254 & 1 & & & & \\
\hline $\mathrm{Mn}$ & 0.129 & 0.163 & -0.258 & 0.045 & 0.141 & -0.251 & -0.026 & 0.188 & 1 & & & \\
\hline $\mathrm{Fe}$ & 0.086 & -0.384 & 0.199 & -0.07 & -0.558 & 0.386 & 0.486 & -0.299 & 0.059 & 1 & & \\
\hline Moisture & -0.17 & $0.899^{* *}$ & -0.218 & -0.052 & 0.468 & -0.5 & 0.287 & $0.965^{\star *}$ & 0.156 & -0.217 & 1 & \\
\hline TAP & 0.048 & $0.764^{\star *}$ & -0.091 & -0.165 & 0.273 & -0.409 & 0.446 & $0.900^{* *}$ & 0.065 & -0.044 & $0.956^{* *}$ & 1 \\
\hline
\end{tabular}

${ }^{*}$ Significant $p<0.05$; Total actinomycetes population (TAP)

Table 3- Phenotypic and biochemical characteristics of isolated actinomycetes

\begin{tabular}{|c|c|c|c|c|c|c|c|c|}
\hline \multicolumn{9}{|c|}{ Morphological } \\
\hline 1 & Aerial mycelium & - & + & $+/-$ & + & $+/-$ & - & + \\
\hline 2 & Substrate mycelium & + & + & + & + & + & + & + \\
\hline 3 & Conidia & - & Long chain of spores & $+/-$ & Single spore & Short chain of spores & Single spore & + \\
\hline 4 & Gram staining & + & + & + & + & + & + & + \\
\hline \multicolumn{9}{|c|}{ Biochemical } \\
\hline 1 & Citrate utilization & $+/-$ & $+/-$ & $+/-$ & $+/-$ & $+/-$ & $+/-$ & $+/-$ \\
\hline 2 & Starch hydrolysis & + & + & + & + & + & $+/-$ & + \\
\hline 3 & Gelatin hydrolysis & + & $+/-$ & + & + & + & + & + \\
\hline 4 & Nitrate reduction & $+/-$ & + & $+/-$ & + & + & + & + \\
\hline 5 & Urea hydrolysis & $+/-$ & $+/-$ & + & $+/-$ & - & $+/-$ & + \\
\hline 6 & Melanin production & - & + & - & - & - & - & - \\
\hline \multicolumn{9}{|c|}{ Chemotaxonomic } \\
\hline 1 & DAP isomer & meso-DAP* & L-DAP* & meso-DAP & meso-DAP & meso-DAP & meso-DAP & meso-DAP \\
\hline
\end{tabular}

+ Positive; - Negative; +/- Positive Negative; " $m e s o-D A P=$ meso- Diaminopimelic Acid; L- DAP =L- Diaminopimelic Acid 
Table 4- The total count of actinomycetes and occurrence of genera isolated from soil samples of Kodagu region.

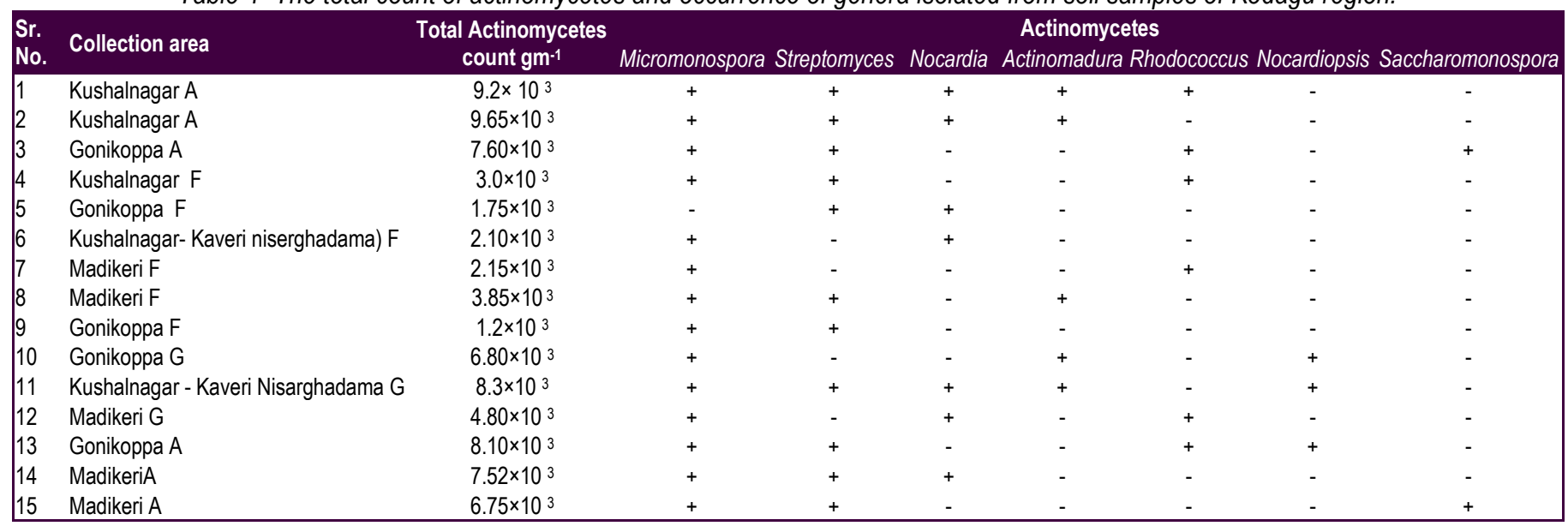

Agriculture field (A); Grass land (G); Forest (F)

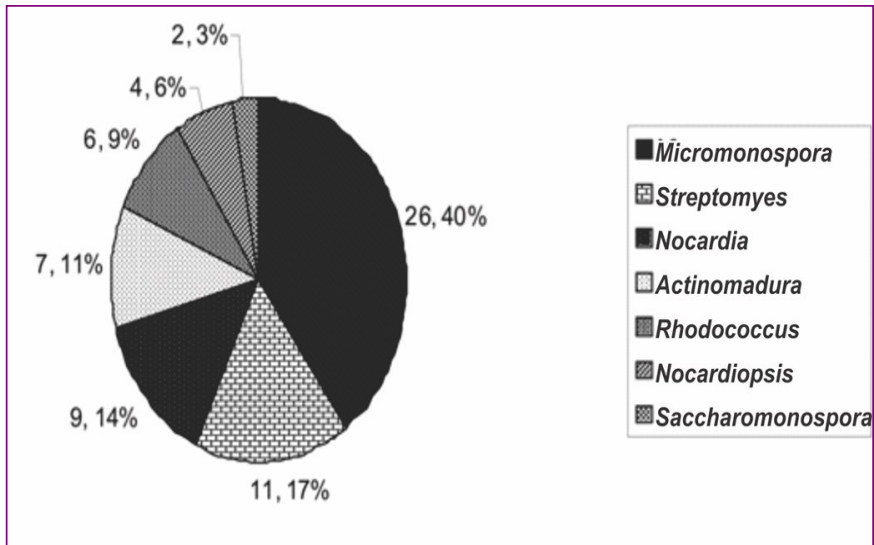

Fig. 2- Percent Frequency of actinomycetes genera from soil samples of Kodagu district

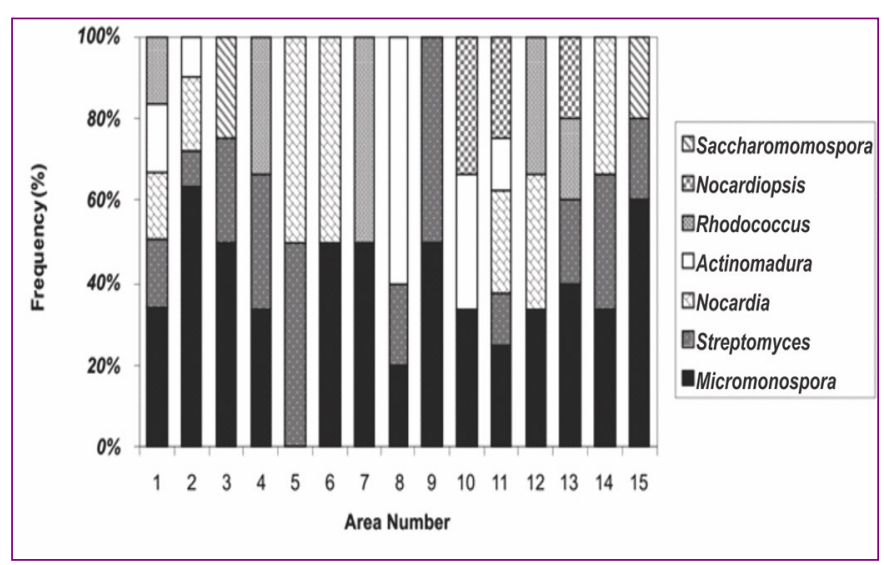

Fig. 3- Actinomycetes Frequency in 15 studied areas of Kodagu district

Diversity and richness of actinomycetes genera isolated from collected samples, gave an idea about the distribution of actinomycetes in all the study area. Site 1 and 11 recorded the highest value for genera richness and 5, 6, 7 and 9 revealed lowest in its value. Value of richness increased with the increase of organic carbon, copper and moisture content of soil [Table-1], [Table-4]. Generic diversity was found to be proportionate with genera richness [Fig-4]. Among 158 actinomycetes isolated from all sites, 138 (87.34\%) isolates showed antimicrobial activity against one or more test or- ganisms upon primary screening. Among these, 36(26.08\%) isolates positive were active against Gram-positive bacteria, 15 $(10.87 \%)$ against Gram-negative bacteria, $87(63.04 \%)$ against both Gram-positive and Gram-negative bacteria respectively. In general, among 138 selected isolates screened, 112(81.15\%) showed activity against Staphylococcus aureus, 86(62.31\%) against Bacillus subtilis, 64(46.37\%) against Escherichia coli, 72 (52.17\%) against Enterobacter aerogenes, 30(21.73\%) against Aspergillus niger respectively [Fig-5].

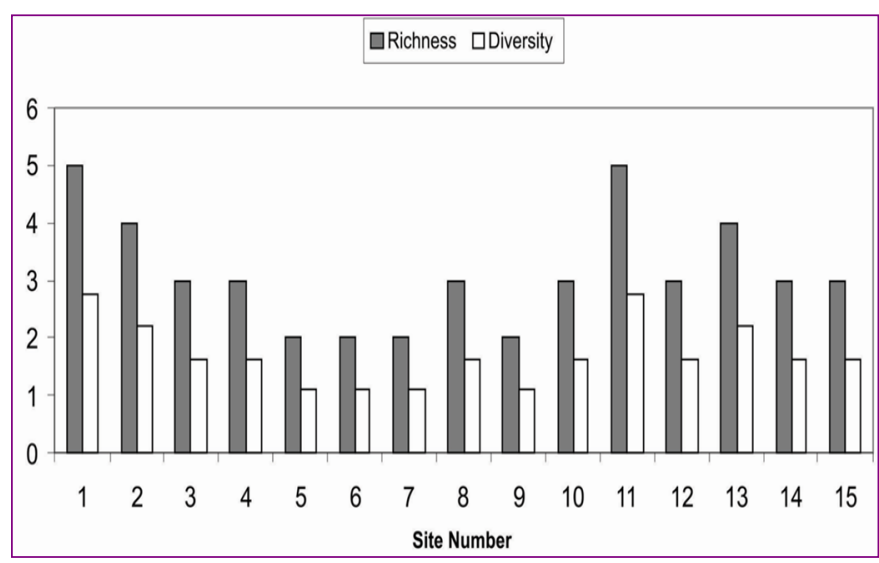

Fig. 4- The richness and diversity of common genera of actinomycetes in Kodagu district

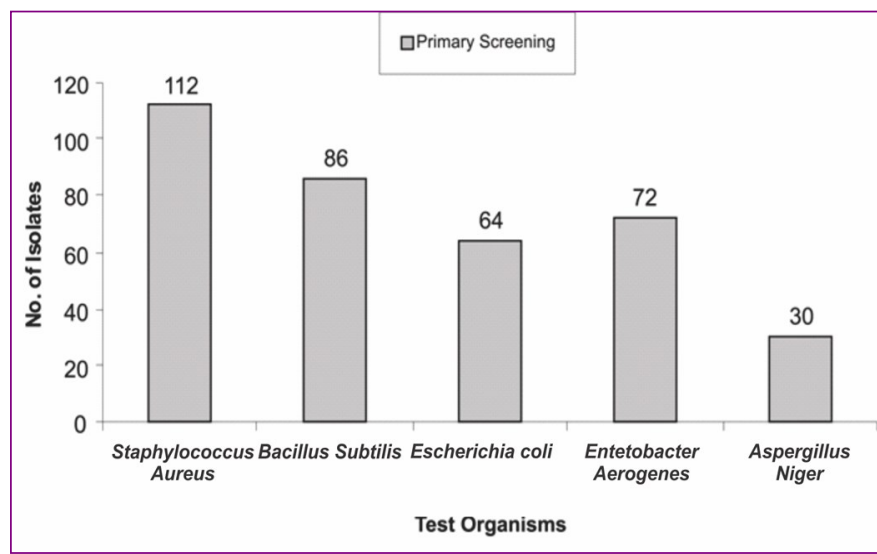

Fig. 5- Number of actinomycetes from soil of Kodagu district showing antimicrobial activity by primary screening 


\section{Discussion}

Actinomycetes have been intensively surveyed in several underexplored environments, niche or extreme habitats in various parts of the world in the last few decades. Some works on the diversity of actinomycetes have been reported from different habitats around the world [6,22-26]. Due to large geographical demonstration there is also variation in soil type and their content. Hence, it is quite likely that the distribution of antibiotic producing actinomycetes is also variable. The results described in this paper are based on isolation, screening and identification of diverse antimicrobials producing actinomycetes of soil collected from different areas of Kodagu. The study revealed that, there was correlation co-efficient between physico-chemical properties of soil and total number of actinomycetes population (TAP) in the soil samples and further revealed about the actinomycetes occurring in high population especially in sites with high percentage of moisture, organic carbon and Copper [6,23-27]. This finding is confirmed that the actinomycetes population and distribution dynamics are often influenced by the physicochemical parameters and available nutrients in the ecosystem [26]. All the soil samples had pH neutral to slightly alkaline which could be responsible for actinomycetes survival and were propagation [23]. Good number of isolates were obtained from different soil samples of Kodagu district. A total of 158 actinomycetes were isolated and screened for antimicrobial activity. The results of primary screening revealed that the most of the isolates were effective against Gram- positive bacteria (Staphylococcus aureus and Bacillus subtilis) than Gram- negative bacteria (Escherichia coli and Enterobacter aerogenes) respectively. The purpose of primary screening was to evaluate the antagonistic isolates of actinomycetes against test organisms for their antimicrobial properties. Out of 158 actinomycetes isolated, 65(47\%) isolates showed significant antimicrobial activities (at least against three test organisms) were identified. Seven actinomycetes genera were recovered from different soil samples of Kodagu district. The study found that, several non Streptomycetes genera (rare actinomycetes) such as Micromonospora, Nocardia, Rhodococcus, Actinomadura, Nocardiopsis, Saccharomonospora beside Streptomyces were isolated $[25,26]$. The investigation also showed that the majority of soil bioactive isolates were Micromonospora and site 2 recorded the highest frequency percentage. Occurrence of Micromonospora was highly correlated with moisture content of soil from which it was isolated. This finding is in confirmation with the results by other investigators [23,28-29]. Apart from Micromonospora, the genus Streptomyces was the second bioactive genera frequently appeared on medium used for isolation. The dominance of Streptomyces among actinomycetes genera especially in soils has also been reported by many researchers [23-29]. Diversity and richness of bioactive genera isolated from collected soil samples, gave an accountability about the distribution of actinomycetes in all the study areas. Variation in the distribution of actinomycetes, frequency, richness and diversity of genera of actinomycetes indicated that edaphic factors in combination with other environmental properties play an important role in creation of specific niches for survival and preservation of actinomycetes in these regions.

\section{Conclusion}

The present study indicated that, Kodagu region of Karnataka state posses diverse groups of antibiotic producing actinomycetes and could be potential sources of bioactive antibiotics.

\section{Conflict of Interest}

All the authors disclose that there is no competing conflict of interest among them.

\section{References}

[1] Berdy J. (2005) J. Antibiot., 58 (1), 1-26.

[2] Pecznska Czoch W. and Mordaski M. (1988) Actinomycetes in Biotechnology, Academic Press London, 219-283.

[3] Hopwood D.A., Kieser T., Bibb M.J., Buttner M.J. and Chater K. F. (2000) Practical Streptomyces Genetics, John Innes Foundation Norwich, UK.

[4] Duraipandiyan V., Sasi A.H., Islam V.I.H., Valanarasu M. and Ignacimuthu S. (2010) J. Med. Mycol., 20(1), 15-20.

[5] Ravikumar S., Inbaneson S.J., Uthiraselvam M., Priya S.R., Ramu A. and Banerjee M.B. (2011) J. Pharm. Res., 4(1), 294296.

[6] George M., George G. and Hatha A.A.M. (2010) South Pacific J. Nat. Appl. Sci., 28(1), 52- 57.

[7] Jackson M.L. (1973) Soil Chemical Analysis, Prentice Hall of India Pvt. Ltd., New Delhi, 388- 393.

[8] Lindsay W.L. and Norwell A. (1978) Soil Sci. Soc. Am. J., 42 (3), 421- 428.

[9] Saadoun I., Al-Momani F., Malkawi H.I. and Mohammad M.J. (1999) Microbios., 100(395), 41-46.

[10]Tsao P.H., Leben C. and Keitt G.W. (1960) Phytopathology, 50 (1), 88-89.

[11]El-Nakeeb M.A. and Lechevalier H.A. (1963) Appl. Microbiol., 11(2), 75- 77.

[12]Shirling E.B. and Gottlieb D. (1966) Int. J. Syst. Bacteriol., 16 (3), 313-340.

[13]Williams S.T. and Davies F.L. (1965) J. Gen. Microbiol., 38(2), 251-261.

[14]Egorov N.S. (1985) Antibiotic: A Scientific Approach, Mir Publishers, Moscow.

[15]Arasu M.V., Duraipandiyan V., Agastian P. and Ignacimuthu S. (2008) J. Med. Mycol., 18(3), 147-153.

[16]Williams S.T., Sharpe M.E., and Holt J.G. (1989) Bergey's Manual of Systematic Bacteriology, 2nd ed., Williams and Wilkins Company, Baltimore.

[17]Dubey R.C. and Maheshwari D.K. (2002) Practical Microbiology., S. Chand and Company LTD, New Delhi.

[18]Gordon R.E. (1968) The Ecology of Soil Bacteria. Liverpool University Press, Liverpool, England, 293-321.

[19]Waksman S.A. (1950) The Actinomycetes: Their nature, Occurrence, Activities and Importance, Ronald Press Company, New York.

[20]Hasegawa T., Takizawa M. and Tanida S. (1983) J. Gen. Appl. Microbiol., 29(4), 319-322.

[21]Smith R.L. (1986) Elements of Ecology, 2nd ed., Harper and Row Publishers, New York.

[22]Lee J.Y. and Hwang B.K. (2002) Can. J. Microbiol., 48(5), 407417.

[23]Mansour S.R. (2003) Pak. J. Biol. Sci., 6(7), 721-728.

[24]Vijayakumar R., Muthukumar C., Thajuddin N., Panneerselvam 
A. and Saravanamuthu R. (2007) Actinomycetologica, 21(2), 59 $-65$.

[25]Wang Y., Zhang Z.S., Ruan J.S., Wang Y.M. and Ali S.M. (1999) J. Ind. Microbiol. Biotechnol., 23(3), 178-187.

[26]Xu L., Li Q. and Jiang C. (1996) Appl. Environ. Microbiol., 62 (1), 244-248.

[27]George M., Anjumol A., George G. and Hathav A.A.M. (2012) Afr. J. Microbiol., 6(10), 2265- 2271.

[28]Williams S.T. and Wellington E.M.H. (1982) Actinomycetes, Methods of Soil Analysis, Madison, USA, 2, 969-987.

[29]Takizawa M., Colwell R.R. and Hill R.T. (1993) Appl. Environ. Microbiol., 59(4), 997-1002. 